\title{
Kinetics of integrin expression in the mouse model of proliferative retinopathy and success of secondary intervention with cyclic RGD peptides
}

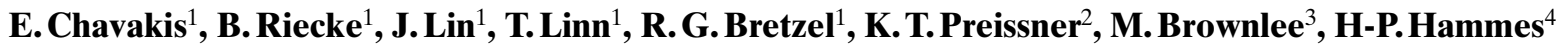 \\ ${ }^{1}$ III Medical Department, Justus-Liebig-University, Giessen, Germany \\ ${ }^{2}$ Institute for Biochemistry, Justus-Liebig-University, Giessen, Germany \\ ${ }^{3}$ Diabetes Research Departments of Medicine and Pathology, Albert Einstein College of Medicine, New York, USA \\ ${ }^{4}$ Vth Medical Clinic, Medical Faculty, University of Heidelberg, Mannheim, Germany
}

\section{Abstract}

Aims/hypothesis. Vitronectin-receptor-type integrins $\left(\alpha_{\mathrm{v}} \beta_{3}\right.$ and $\left.\alpha_{\mathrm{v}} \beta_{5}\right)$ are thought to be involved in the selective ablation of tumorigenic and other pathologic angiogenesis. Specifically, it has been shown that ligation inhibition of the $\alpha_{\mathrm{v}}$-type integrins with cyclic penta-peptid peptide inhibits proliferative retinopathy by almost $80 \%$ in a hypoxia-induced mouse model.

Methods. On the basis of growth factor and integrin expression dynamics in this model, secondary intervention approaches with cyclic RGDfV peptide were investigated.

Results. $\alpha_{\mathrm{v}}$-integrin expression started immediately after induction of hypoxia (at postnatal day 12, p12) and persisted only during the initial period of neovascularization (until day p14). Vascular endothelial growth factor (VEGF) expression started at high values immediately after return of the mice into room air, and dropped rapidly to low values beyond day 13. In contrast, basic fibroblast growth factor (bFGF) was predominantly expressed during the phase of maximum angiogenesis which was noted between day p17 and 19. Based on these findings, cyclic penta peptide was administered subcutaneously at varying doses $(2-20 \mu \mathrm{g} / \mathrm{kg} /$ day $)$ for 5 days beginning either at day p14 (early intervention) or at day p17 (late intervention). Early secondary intervention showed a dose-dependent reduction of new vessels with maximum inhibition of $57 \%$ (control $68.08 \pm 3.21$ nuclei/section compared with RGDfVtreated $29.35 \pm 2.39$ nuclei/section; $p<0.0001$ ), whereas late secondary intervention had no effect. Conclusion/hypothesis. These data indicate that angiogenesis-related $\alpha_{\mathrm{v}}$-integrin expression is VEGFrather than bFGF-dependent, and the efficacy of cyclic penta-peptid (RGDfV)-treatment in proliferative retinopathy is only effective as long as the $\alpha_{\mathrm{v}}$-integrin target is prominently expressed. [Diabetologia (2002) 45: 262-267]

Keywords Endothelial proliferation, retinopathy, alpha $_{\mathrm{v}}$-type integrins, microvessels, vascular endothelial growth factor, basic fibroblast growth factor.
Received: 3 September 2001 and in revised form: 22 October 2001

Corresponding author: H-P. Hammes, Vth Medical Clinic, Medical Faculty, University of Heidelberg, Mannheim, Germany, e-mail: hans-peter.hammes@med5.ma.uni-heidelberg. de

Abbreviations: ROP, Retinopathy of prematurity; VEGF, vascular endothelial growth factor; bFGF, basic fibroblast growth factor; $R G D f V$, cyclic penta-peptid
Angiogenesis during adulthood is limited to a few tissue sites such as the ovary and the uterus (during reproduction) and the skin (during wound healing) [1, 2]. However, despite the normal low turnover rate, adult endothelial cells are permanently able to form new blood vessels during pathologic angiogenesis which is involved in a variety of diseases such as tumor formation and metastasis, inflammatory skin and joint diseases [3], and in ocular diseases such as proliferative diabetic retinopathy [4]. These conditions require the transformation of the mature resting endothelial cell to an angiogenic endothelial pheno- 
type. While physiologic angiogenesis is a self-limiting process, pathologic angiogenesis is a self-perpetuating process which requires active intervention. Angiogenesis from established quiescent vessels is a tightly regulated, complex sequence of events involving pericellular proteolysis, migration and proliferation of cells, final tube formation and recruitment of periendothelial cells [5]. Each step of this process offers therapeutic targets, but the complexity of the process and the multiplicity of factors involved at the induction level makes single target approaches difficult. This makes the inhibition of the downstream pathway of angiogenesis, which includes the adhesive interactions of angiogenic endothelial cells with components of the extracellular matrix, an alternative [6]. The approach is based on findings that endothelial cells of the angiogenic phenotype express specific adhesion receptors, predominantly of the vitronectintype integrins $\left(\alpha_{\mathrm{v}} \beta_{3}\right.$ and $\left.\alpha_{\mathrm{v}} \beta_{5}\right)$ [7], and that small peptide antagonists of this integrin system reduce by almost $80 \%$ new vessels in the eyes of mice with experimental proliferative retinopathy [8]. Based on the unique linear integrin-binding motif RGD on several extracellular matrix ligands, stabilized low molecular weight cyclic structures containing a variety of different flanking regions have been constructed to serve as potential inhibitors of cell adhesion. Among these, the cyclic RGDfV-peptide was found to be particularly resistant against degradation, to show a more than 10000 -fold higher affinity compared with natural integrin ligands as well as selectivity for $\alpha v$-integrins [9-13]. Due to these properties, relatively low doses of the peptide are therapeutically effective, while higher doses might not produce detectable side effects as shown earlier [8]. Despite its short-term nature, the mouse model mimics all essential steps of human proliferative retinopathy of various causes.

In the clinical setting, however, patients with proliferative ocular diseases such as diabetic retinopathy sometimes have pre-existing neovascularization, in particular when recommended screening intervals have not been considered. The extent to which active neovascularization in the retina is still susceptible to small peptide antagonists of the integrin system is still not clear. In order to obtain a rationale for secondary interventions, we studied the kinetics of angiogenesis in the retina by analysing the expression of $\alpha_{\mathrm{v}}$-integrins and VEGF, bFGF in the ROP mouse model. Based on these findings, we examined whether ligation inhibition of the integrin system by the cyclic RGDfV antagonist is still effective as an interventional approach. Our results indicate that the effect of secondary intervention is closely associated to the expression $\alpha_{\mathrm{v}}$-integrins and is not related to the extent of neovascularization.

\section{Materials and methods}

All experiments in this study were done according to the guidelines of the statement for animal experimentation issued by the Association for Research in Vision and Opthalmology and were approved by the local board for animal care.

Animals. C57BL/6 J mice (Charles River, Sulzfeld, Germany) were used throughout the study.

Reagents. Cyclo-RGDfV peptide was obtained from Bachem Biochemica (Heidelberg, Germany). The polyclonal antibody against the mouse $\alpha_{\mathrm{v}}$-integrin subunit is described elsewhere [14] and was kindly provided by Dr. B. Imhof (University Hospital, Geneva, Switzerland). The antibody was raised against mouse $\alpha v \beta 3$-integrin and also recognizes the $\alpha v \beta 5$-integrin homologue.

Mouse model of hypoxia-induced retinal neovascularization (ROP model). Retinal fluorescein angiograms and quantitation of neovascular nuclei were done as described [15, 8]. Briefly, 7day-old (p7) C57BL/6 J mice were exposed to $75 \%$ oxygen for 5 days with their nursing mothers in an incubator (Stuart Scientific, Redhill, UK). At p12, the mice were returned to room air. Unexposed control mice were kept in room air under identical conditions including light cycle and temperature.

Time course of neovascularization in the ROP model. To determine the maximum response of neovascularization in the ROP model, the time course of neovascularization was done using 10 mice in each group to measure angiogenesis at days $\mathrm{p} 12$, p14, p17, p19, p22, p26, and p28 after the 5-day period of hyperoxia. We also used serial fluorescein angiographies of mice at days p11 (ie during the last day of hyperoxia exposure), $\mathrm{p} 12$, p13, and p 14 to confirm the onset of the neovascular process in comparison with previously published data.

Western blot analysis. To determine the temporal expression pattern of the $\alpha_{\mathrm{v}}$-type integrins in relation to two of its inducers, VEGF and bFGF, Western-blot analysis of retinal protein extracts of four retinae from four different animals for each time point was carried out using the following antibodies: a polyclonal rabbit antibody directed against mouse $\alpha_{\mathrm{v}} \beta_{\mathrm{x}}$-integrin $(0.1 \mu \mathrm{g} / \mathrm{ml})$, a polyclonal rabbit antibody directed against the N-terminal domain of VEGF $(0.1 \mu \mathrm{g} / \mathrm{ml}$; Santa Cruz, Ismaning, Germany), a polyclonal rabbit antibody directed against purified bovine brain bFGF with high specificity against mouse bFGF [16] $(5 \mu \mathrm{g} / \mathrm{ml})$.

All procedures including incubation with secondary sheep anti-rabbit IgG are described elsewhere [17]. Control mice not exposed to high oxygen were killed on days $12,13,14,15$, 17 , and 26 after birth, and retinal extracts of four retinae from four different animals for each time point were exposed to the antibodies described above under identical conditions.

Systemic treatment with cyclic RGDfV peptide. Based on the data obtained from the time course of retinopathy in the ROP model (see Fig. 1), two treatments were designed: firstly, early secondary intervention of subcutaneous injections of either saline alone (vehicle) or cyclic RGDfV peptide $(10,20,50$, and $100 \mu \mathrm{g})$ in $50 \mu \mathrm{l}$. These were done two times a day for 5 days from day p14 to p19, ie during the period of the steepest increase of neovascularization. The other treatment was late secondary intervention initiated for 5 days from day $\mathrm{p} 17$ to $\mathrm{p} 22$, ie at the maximal neovascular response. Preliminary experiments revealed no differences in the outcome between $0.9 \%$ saline and the RADfV control peptide. 


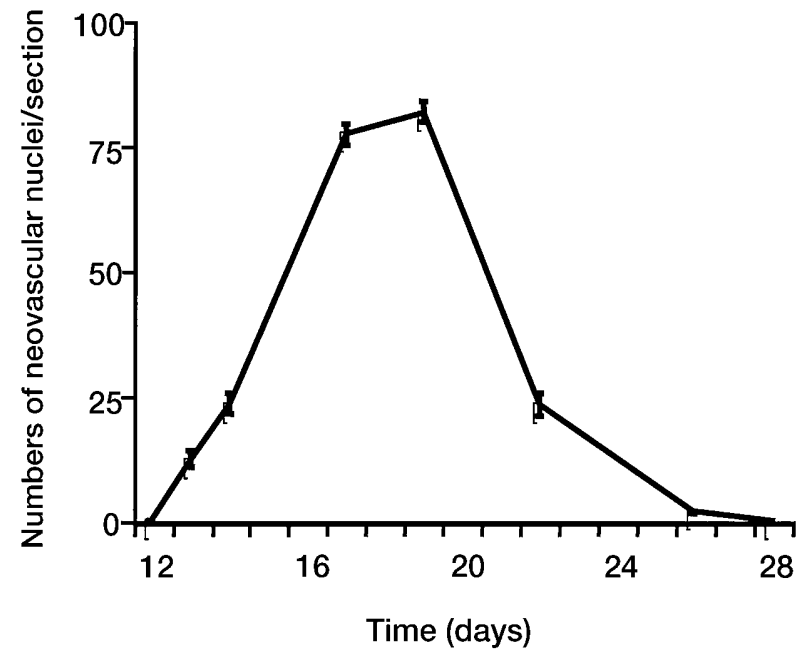

Fig. 1. Time course of retinal neovascularization in the mouse ROP model. Following the 5 days hyperoxygenation period (days p7-p12), mice were returned to room air, and neovascular nuclei were consecutively measured in retinae at the indicated time points. Note that the maximal extent of angiogenesis was during day p17-19

Statistics. All results were expressed as the means \pm SEM of at least three independent determinations unless otherwise stated. Analysis of variance and the unpaired Student's $t$ test was used for statistical analysis (GraphPad, Instat, San Diego, Calif., USA). A $p$ value of less than 0.05 was considered to be statistically significant.

\section{Results}

Time course of retinal neovascularization. In order to determine the kinetics of new blood vessel formation in quantitative terms, retinal neovascular nuclei of mice, exposed for 5 days (p7-p12) to $75 \%$ oxygen were evaluated, beginning at the time of return to room air. Fluorescein angiograms revealed that the first neovascular tufts appeared at day p13 (not shown). The numbers of preretinal neovascular nuclei/section were $23 \pm 2.1$ at day p14, and peaked between day p17 and day p19 (p17: 77.2 \pm 2.0 , p19: $81.5 \pm 2.2$ nuclei/section; $p$ ns) with subsequent regression to $1.5 \pm 0.1$ at day $\mathrm{p} 26$. At day $\mathrm{p} 28$ retinal neovascularization had regressed completely in all animals examined (Fig. 1).

Time course of expression of $\alpha_{v}$-integrins and growth factors. Retinal extracts from oxygen-exposed mice were analysed at different time points after re-exposure to normoxia for the presence of $\alpha_{\mathrm{v}}$-integrin, VEGF, and bFGF by Western blot analysis using specific antibodies. Figure 2 shows a strong expression of the integrins immediately upon return of the animals to room air. The integrin protein concentrations remained higher until day p14 after which they declined to baseline for the subsequent days (p15-p26). Con-

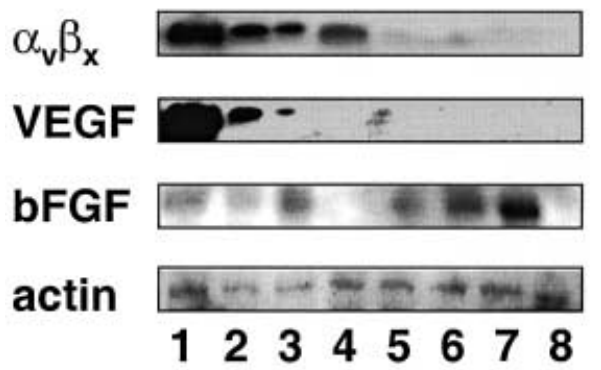

B
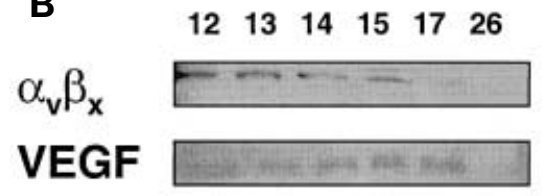

bFGF

actin

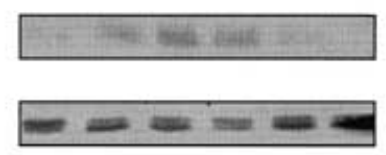

$\begin{array}{llllll}1 & 2 & 3 & 4 & 5 & 6\end{array}$

Fig. 2(A, B). Time course of synthesis of $\alpha_{\mathrm{v}}$-integrin, VEGF, and bFGF protein during retinal neovascularization. A Equal amounts of retinal extracts from four eyes at the time points indicated were subjected to Western blot analysis and developed with specific antibodies against $\alpha_{\mathrm{v}}$-type integrins, VEGF, and bFGF as described in the Materials and methods section. In parallel, analysis for beta actin was done. B Expression of VEGF, bFGF, and $\alpha_{\mathrm{v}}$-type-integrin in relation to beta actin in the normal developing mouse retina for comparison with (A). Retinal extracts from four eyes were pooled and subjected to blot analysis as described

sistent with ongoing physiologic angiogenesis in the developing retina, non-exposed normal mice had low but detectable concentrations of integrins discernible until day p17.

VEGF protein expression was strongest shortly after the mice had returned to room air (p12-p13), and VEGF decreased rapidly and reached baseline values at day $\mathrm{p} 14$, ie preceding the decrease of the $\alpha_{\mathrm{v}}$-type integrin (Fig. 2). Normal mice had very low concentrations of VEGF protein during days $\mathrm{p} 12$ to $\mathrm{p} 17$. At day p 26, VEGF expression was below the detection limit.

The strong protein expression level of bFGF was detectable between day $\mathrm{p} 12$ and $\mathrm{p} 15$. At day $\mathrm{p} 17$, during the maximum of neovascularization, bFGF expression was further increased (Fig. 2). At day p26, no bFGF was detected. In normal mouse eyes, bFGF was present between days p13 and p15.

Secondary interventions with cyclic $R G \mathrm{D} f V$ peptide. Following exposure to high oxygen, all retinae 

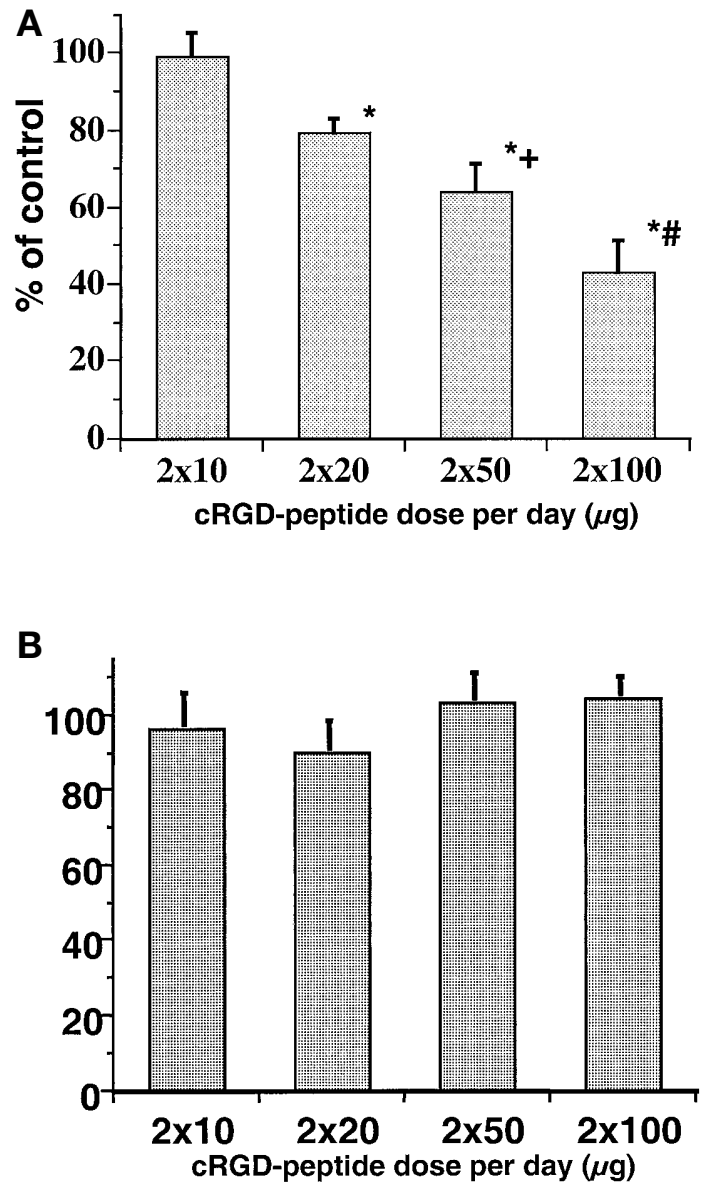

Fig.3(A, B). Therapeutic efficacy of secondary intervention with cyclic RGdfV peptide in the ROP model. A Dose-response of treatment with cyclic RGDfV peptide initiated at day p14 for 5 days (early intervention) compared with salinetreated mice. Quantitation of neovascular nuclei was done at day p19. B Dose-response of treatment with cyclic RGDfV peptide initiated at day $\mathrm{p} 17$ for 5 days (late intervention) compared with saline-treated animals. Morphometric analysis was done at day $\mathrm{p} 22$. All data are expressed as per cent of control \pm SEM; $*$ indicates statistical significance $(p<0.05)$ compared with sham-treated control; + indicates statistical significance vs $2 \cdot 20 \mu \mathrm{g} / \mathrm{day}$; \# indicates statistical significance compared with $2 \cdot 50 \mu \mathrm{g} /$ day

showed a marked central avascular zone confirming considerable angiogenic stimulation due to vasoobliteration. Based on the time course of the angiogenic response in the ROP model, two secondary intervention treatments for a duration of 5 days each were designed. Early intervention with a dosage of $2 \cdot 2-20 \mathrm{mg} / \mathrm{kg}$ body weight was initiated at day $\mathrm{p} 14$, when the steepest increase in retinal neovascularization had occurred. Despite the delayed treatment with cyclic RGDfV peptide, we found a linear doseresponse relation of inhibition of retinal angiogensis. While a threshold of inhibition was determined at a dose of $2 \cdot 20 \mu \mathrm{g} /$ day (ie $2 \cdot 4 \mathrm{mg} / \mathrm{kg}$ ) (mock-treated, $71.25 \pm 2.08$ nuclei/section vs RGDfV-treated, $56.40 \pm 2.57$ nuclei/section; $p<0.0001)$, maximum in- hibition was observed with the highest dose ( 2 . $100 \mu \mathrm{g} /$ day) and was $56.9 \%$ (mock-treated, $68.08 \pm$ 3.21 nuclei/section vs RGDfV-treated, $29.35 \pm 2.39$ nuclei/section; $p<0.0001$ ) (Fig. 3A).

Late secondary intervention with the identical dosage and frequency of injections of the integrin antagonist was initiated at day p17, ie at the point of maximal neovascular response in the ROP model. As depicted in Figure 3B, there was no therapeutic effect of the peptide on the established neovascular process in the retina. Thus, beginning treatment of retinal proliferation at the time of its maximum is no longer effective.

\section{Discussion}

Our data show that retinal neovascularization in the ROP model begins $24 \mathrm{~h}$ after initiation of hypoxia as the angiogenic stimulus. Proliferative retinopathy degree peaks between day p17 and p19, and regresses completely around day p26. These data confirm previous assessments [13], but were needed because of the possible variability in the extent of retinal response.

According to our data, VEGF appears to be primarily involved in the initial proliferative response, while bFGF is upregulated during the maximum neovascular response. Interestingly, $\alpha_{\mathrm{v}}$-type integrin expression is strongly upregulated during the early phase of neovascularization and is completely absent during the period when new vessels become abundant in the retina. Consistent with the time course of integrin expression, a secondary intervention with cyclic RGDfV peptides is only effective early during the neovascularization period.

VEGF, a well-described hypoxia-induced growth factor $[18,19]$, is a major inducer of ocular neovascularization, mediating its effect by high-affinity VEGF receptors [20-22]. It has been shown in the mouse ROP model that VEGF mRNA expression in Müller and ganglion cells increased $12 \mathrm{~h}$ after hypoxia induction (ie the transition of the animals from the hyperoxic to the normoxic environment) approximately three-fold and persists until p17 when mRNA is still increased 1.5-fold above baseline expression, suggesting that VEGF could be important during the entire neovascularization process [23]. The reported time course of mRNA expression is inconsistent with our present data on VEGF protein expression probably because of the differences in sensitivities of the methods.

In contrast, the second growth factor, bFGF, studied in relation to ocular neovascularization in the ROP model is expressed throughout the entire angiogenesis process. bFGF is upregulated around the maximal neovascular response in the ROP model in the absence of VEGF, suggesting that bFGF is a pre- 
dominant growth factor involved in the propagation of the neovascular response to ischaemia. Accordingly, despite the lack of a signal sequence, bFGF is increased in retinae with proliferative retinal diseases $[24,25]$. The temporal but distinct expression and distribution of both growth factors in the ROP model contradicts a direct relation between bFGF and VEGF induction. Based on in vitro data it appears possible that bFGF can sensitize endothelial cells to VEGF by increasing the expression of the receptor tyrosine kinase flk-1 [26]. Preliminary data in the ROP model, however, indicate that flk-1 is downregulated in parallel with VEGF starting at day p14 (Hammes et al., unpublished observations).

Based on antibody blocking experiments, at least in the chick chorioallantoic membrane model or the rabbit cornea pocket assay, stimulation of angiogenesis by bFGF leads to the expression of $\alpha_{\mathrm{v}} \beta_{3}$-integrin, while the stimulation by VEGF induces the expression of $\alpha_{\mathrm{v}} \beta_{5}$-integrin [27]. Such a clear distinction between two different growth factor-related pathways of integrin induction were not observed in the ROP model because the expression of the entire pool of $\alpha_{\mathrm{v}}$-integrin protein appeared to correlate with VEGF rather than bFGF expression. The downregulation of the $\alpha_{\mathrm{v}}$-type integrins found after day p14 indicates the predominance of the VEGF-dependent pathway in the initiation of ischaemia induced proliferative retinopathy, whereas an $\alpha_{\mathrm{v}}$-integrin-independent but bFGF-dependent pathway appears to be operative during propagation of the process.

Our data are in accordance with other findings in a mouse tumor model. Previous studies showed that angiogenic endothelial cells are still sensitive to ligation inhibition when they have entered the cell cycle [6]. They administered cRGD peptide i.v. $24 \mathrm{~h}$ after the onset of angiogenesis and found an increasing number of apoptotic cells over the next 24 to $48 \mathrm{~h}$ as well as a substantial regression of tumours. These data implicate that a delay in the initiation of the treatment does not impair efficacy as long as integrins are expressed as is demonstrated in the present work. These data further support the notion that endothelial cell survival is dependent on adhesion through vitronectin-type integrins [28].

Overlapping functionality and compensation are two aspects of integrin function, recently brought to attention by work, which reported that mice with a null mutation of the $\alpha_{\mathrm{v}}$-integrin subunit die in utero from placental defects [29]. A total of $29 \%$ of these mice developed to term showing extensive angiogenesis, and their main defects were cerebral and intestinal haemorrhages, indicating organ-specificity of the $\alpha_{v}$-integrin system and compensation by other integrins. The efficacy of ligation inhibition of the $\alpha_{v^{-}}$ type integrin system in proliferative retinopathy can be reconciled with these data from knockout experiments because postnatal and pathological angiogene- sis in specific organs such as the retina differ from developmental angiogenesis with regard to mechanisms of initiation and progression.

Taken together, our data indicate that ligation inhibition of the $\alpha_{\mathrm{v}}$-type integrin system as a secondary treatment is promising provided the respective targets are present in specific clinical settings. Although the application of these findings to treat human diseases might be problematic, it has been shown that $\alpha_{\mathrm{v}}$-type integrins are expressed in ongoing or even established neovascularization in the eye from patients with proliferative diabetic retinopathy [30], suggesting that the approach could be favourable because of the chronically present target integrin.

Acknowledgements. This work was supported by grants from the Juvenile Diabetes Foundation International and from the German Research Association (Deutsche Forschungsgemeinschaft).

\section{References}

1. Eliceiri BP, Cheresh DA (1999) The role of alphav integrins during angiogenesis: insights into potential mechanisms of action and clinical development. J Clin Invest 103: $1227-1230$

2. Risau W (1997) Mechanisms of angiogenesis.Nature 386: 671-674

3. Folkman J (1995) Angiogenesis in cancer, vascular, rheumatoid and other disease. Nat Med 1: 27-31

4. Patz A (1978) Current concepts in ophthalmology. Retinal vascular diseases. N Engl J Med 298: 1451-1454

5. Hanahan D, Folkman J (1996) Patterns and emerging mechanisms of the angiogenic switch during tumorigenesis. Cell 86: 353-364

6. Brooks PC, Montgomery AM, Rosenfeld M et al. (1994) Integrin alpha $\mathrm{v}$ beta 3 antagonists promote tumor regression by inducing apoptosis of angiogenic blood vessels. Cell 79: 1157-1164

7. Brooks PC, Clark RA, Cheresh DA (1994) Requirement of vascular integrin alpha $\mathrm{v}$ beta 3 for angiogenesis. Science 264: 569-571

8. Hammes HP, Brownlee M, Jonczyk A, Sutter A, Preissner KT (1996) Subcutaneous injection of a cyclic peptide antagonist of vitronectin receptor-type integrins inhibits retinal neovascularization. Nat Med 2: 529-533

9. Ruoslahti E, Pierschbacher MD (1987) New perspectives in cell adhesion: RGD and integrins. Science 238: 491-497

10. Lohof E, Planker E, Mang C et al. (2000) Carbohydrate derivatives for use in drug design: Cyclic alpha(v)-selective RGD peptides. Angew Chem Int Ed 39: 2761-2764

11. Aumaillay M, Gurrath M, Müller G, Calvete J, Timpl R, Kessler H (1991) Arg-Gly-Asp constrained within cyclic pentapeptides: strong and selective inhibitors of cell adhesion to vitronectin and laminin fragment P1. FEBS Lett 291: 50-54

12. Pfaff M, Tangemann K, Müller B et al. (1994) Selective recognition of cyclic RGD peptides of NMR defined conformation by alpha IIb beta 3 , alpha $\mathrm{V}$ beta 3 , and alpha 5 beta 1 integrins. J Biol Chem 269: 20233-20238

13. Hauber R, Grathas R, Diefenbach B, Goddman SL, Jonczyk A, Kessler H (1996) Structural and functional aspects of RGD-containing cyclic pentapeptides as highly potent 
and selective integrin avb3 antagonists. J Am Med Soc 118: 7461-7472

14. Imhof BA, Weerasinghe D, Brown EJ et al. (1997) Cross talk between alpha(v)beta3 and alpha4beta1 integrins regulates lymphocyte migration on vascular cell adhesion molecule 1. Eur J Immunol 27: 3242-3252

15. Smith LE, Wesolowski E, McLellan A et al. (1994) Oxygen-induced retinopathy in the mouse. Invest Ophthalmol Vis Sci 35: 101-111

16. Matsuzaki K, Yoshitake Y, Matuo Y, Sasaki H, Nishikawa K (1989) Monoclonal antibodies against heparin-binding growth factor II/basic fibroblast growth factor that block its biological activity: invalidity of the antibodies for tumor angiogenesis. Proc Natl Acad Sci USA 86: 9911-9915

17. Hammes HP, Weiss A, Hess S et al. (1996) Modification of vitronectin by advanced glycation alters functional properties in vitro and in the diabetic retina. Lab Invest 75: 325-338

18. Pe'er J, Shweiki D, Itin A, Hemo I, Gnessin H, Keshet E (1995) Hypoxia-induced expression of vascular endothelial growth factor by retinal cells is a common factor in neovascularizing ocular diseases. Lab Invest 72: 638-645

19. Shima DT, Deutsch U, D'Amore PA (1995) Hypoxic induction of vascular endothelial growth factor (VEGF) in human epithelial cells is mediated by increases in mRNA stability. FEBS Lett 370: 203-208

20. deVries C, Escobedo J, Ueno H, Houck K, Ferrara N, Williams LT (1992) The fms-like tyrosine kinase, a receptor for vascular endothelial growth factor. Science 255: 989-991

21. Millauer B, Wizigmann-Voos S, Schnurch H et al. (1993) High affinity VEGF binding and developmental expression suggest Flk-1 as a major regulator of vasculogenesis and angiogenesis. Cell 72: 835-846
22. Breier G, Clauss M, Risau W (1995) Coordinate expression of vascular endothelial growth factor receptor 1 (flt 1) and its ligand suggests a paracrine regulation of murine vascular development. Dev Dyn 204: 228-239

23. Pierce EA, Avery RL, Foley ED, Aiello LP, Smith LE (1995) Vascular endothelial growth factor/vascular permeability factor expression in a mouse model of retinal neovascularization. Proc Natl Acad Sci U S A 92: 905-909

24. Sivalingam A, Kenney J, Brown GC, Benson WE, Donoso L (1990) Basic fibroblast growth factor levels in the vitreous of patients with proliferative diabetic retinopathy. Arch Ophthalmol 108: 869-872

25. Hanneken A, de Juan E Jr, Lutty GA, Fox GM, Schiffer S, Hjelmeland LM (1991) Altered distribution of basic fibroblast growth factor in diabetic retinopathy. Arch Ophthalmol 109: 1005-1011

26. Pepper MS, Mandriota SJ (1998) Regulation of vascular endothelial growth factor receptor-2 (Flk-1) expression in vascular endothelial cells. Exp Cell Res 241: 414-425

27. Friedlander M, Brooks PC, Shaffer RW, Kincaid CM, Varner JA, Cheresh DA (1995) Definition of two angiogenic pathways by distinct alpha $\mathrm{v}$ integrins. Science 270: 1500-1502

28. Meredith JE Jr, Fazeli B, Schwartz MA (1993) The extracellular matrix as a cell survival factor. Mol Biol Cell 4: 953-961

29. Bader BL, Rayburn H, Crowley D, Hynes RO (1998) Extensive vasculogenesis, angiogenesis, and organogenesis precede lethality in mice lacking all alpha v integrins. Cell 95: 507-519

30. Casaroli Marano RP, Preissner KT, Vilaro S (1995) Fibronectin, laminin, vitronectin and their receptors at newly-formed capillaries in proliferative diabetic retinopathy. Exp Eye Res 60: 5-17 